\title{
SNAPSHOT
}

\section{A drift in the Arctic}

The central Arctic Ocean is a challenging location to reach and to study but plays an important role in the climate system. Covered in sea ice year-round, with midnight sun in the summer and polar night in the winter, it hosts a unique marine and sea-ice ecosystem. By no means is it a static environment; the ice is constantly shifted by the ocean and the winds, creating a unique landscape.

Understanding the Arctic requires observations in the field, as remote sensing is limited, and many processes take place on a smaller scale than can be detected remotely. This is why the German icebreaker RV Polarstern is set to spend a year locked in the ice, collecting measurements that will unravel the key climate processes that take place there. The Multidisciplinary drifting Observatory for the Study of Arctic Climate (MOSAiC) has just set sail from Tromsø, Norway. But this is not the first drift expedition in the Arctic.

In 1893 , a specially strengthened wooden vessel, the Fram, led by Fridtjof Nansen, with Otto Sverdrup as captain, set off aiming to reach the geographic North Pole. The ship entered the ice in the east Arctic, and the explorers firmly locked their vessel in the pack ice to harness the theorized Arctic east-west current. Although they were not successful in reaching the pole, the ship survived 3 years in the ice and proved that the east-west drift could transport a vessel across the Arctic.

The premise of MOSAiC was sparked in 2010 by an idea put forward by Klaus Dethloff of the Alfred Wagner Institute (AWI) in Potsdam, Germany. Markus Rex, head of MOSAiC and expedition leader, recalls that it seemed "too challenging logistically but the idea did not go away." The idea grew, and funding from AWI pushed it into reality. Seventeen nations are now involved in the project, which will study a wide range of questions: the surface energy budget, from the smallscale atmospheric eddies some 10-20 m across to radiative fluxes; the properties of clouds and aerosols; sea ice and its changes across the seasons; the ocean's physical properties; ecosystem functioning through the midnight sun and its all-day light, and the opposing polar night; along with many more. The project aims to "provide

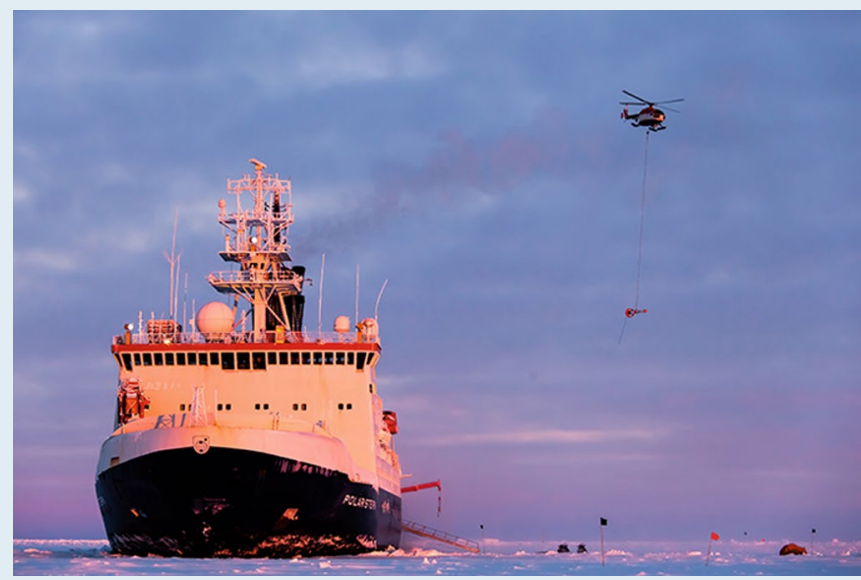

Credit: Alfred-Wegener-Institut/Mario Hoppmann

a robust basis for modelling of the Arctic, [to ultimately provide] improved and more reliable global climate models," says Rex.

The RV Polarstern with her 101 personnel of researchers, logistics support and crew will enter the ice in the Siberian Arctic, around $130-140^{\circ} \mathrm{E}$, with the expectation that by $85^{\circ} \mathrm{N}$ they will be sufficiently into the ice pack to switch off the engines and allow the Arctic to decide their course for the next year. "The start point is the only degree of freedom," says Rex, so it has been planned carefully to give the best chance that the ship remains in the ice for the intended 350 days. Once in the desired position, the expedition will identify a large floe, sufficient to support the desired experimental work, and moor themselves to it.

Mooring to a large ice floe creates a floating laboratory platform, with equipment set up on the ice to take measurements, and scientists collecting a variety of observations - ocean, ice and atmosphere - during the Arctic crossing. About a third of the research during MOSAiC will be ship-based, and twothirds will be conducted on the ice.

The ship will be supported by four icebreakers as well as aircraft for resupply and personnel changes, which will happen every 2-3 months when possible. Aircraft will be used when the ice thickness prevents ship resupply, and this will require construction of a runway on the ice. Resupply will also aid the transfer of collected data back to institutes, allowing further analysis to that started onboard.

Many things have changed in the 126 years since Nansen set off - climate change is altering the Arctic. But many of the challenges of polar exploration remain with unpredictability of the hostile environment. When the Norwegian Polar Institute tried a shorter drift experiment as a precursor of MOSAiC, mostly in the marginal ice zone north of Svalbard, in 2015 onboard the RV Lance, the ship was moored to a large floe, but storms and wind pushed the ship out of the ice pack after only 5 weeks locked in. The team re-entered the ice and ended up spending 111 days overall in the ice pack but needed to tether to different floes through that time as the conditions altered the plans.

The remoteness will offer challenges to the 600 participants over the year, but the opportunity that MOSAiC offers is vast, with many first-time measurements that could lead to exciting breakthrough science. Although there will not be great connection with the outside world, daily updates will be posted on the web app (https:// follow.mosaic-expedition.org) as well as updates on Twitter (@MOSAiCArctic) and Instagram (@mosaic_expedition), including 'picture of the day'.

Bronwyn Wake

Published online: 25 September 2019 https://doi.org/10.1038/s41558-019-0597-3 